\title{
ANÁLISE DO GERENCIAMENTO DE RESÍDUOS SÓLIDOS DA CONSTRUÇÃO CIVIL EM TERESINA, PIAUI ${ }^{1}$
}

Tássio Tanic Leite Lima, UNIFSA ${ }^{2}$ Hebert Rodrigues Araujo, UNIFSA ${ }^{3}$ Acilayne Freitas de Aquino, UNIFSA ${ }^{4}$ Ricardo Augusto de Carvalho Sá, UNIFSA ${ }^{5}$ Rafael Fontenele Sampaio, UNIFSA ${ }^{6}$

\section{RESUMO}

Devido à falta de responsabilidade das empresas no gerenciamento dos resíduos, e o aumento populacional, o volume de Resíduos Sólidos na Construção e Demolição, (RCD's) acabam crescendo com o decorrer do tempo, mesmo existindo leis e normas que regulamentem o gerenciamento dos resíduos, a situação da construção civil ainda apresenta um volume significativo de desperdício, pois a fiscalização ainda é muito deficiente. Este trabalho tem como objetivo, identificar locais para a destinação atual dos resíduos sólidos na cidade de Teresina e quantificar o volume de resíduos gerados. O estudo foi realizado em uma empresa privada, a qual faz a coleta e o transporte dos resíduos sólidos com atuação há 10 anos no mercado, onde se observou as grandes dificuldades no segmento, devido as "baixas" da economia na construção civil e a concorrência com empresas clandestinas que barateiam suas coletas, devido a essas destinarem esses resíduos em locais inadequados. No entanto, mostra-se ainda uma produção no mês, estável, sendo em média de 250 caçambas/mês, recolhendo assim em torno de $1000 \mathrm{~m}^{3} / \mathrm{mês}$, valor significativo de desperdício, pois a fiscalização ainda é muito deficiente, e quantidades que muda no decorrer do ano, devido a se ter mais ou menos construções e reformas.

Palavras-Chave: Construção Civil. Resíduos Sólidos. Teresina. Entulho.

\section{INTRODUÇÃO}

Sendo uma das atividades mais importantes para o desenvolvimento da sociedade e da economia, e estando por cerca de $14 \%$ do PIB nacional, a construção civil é um dos maiores consumidores de matérias-primas naturais, porém, comportando-se ainda, como uma grande geradora de impactos ambientais e na modificação da paisagem e geração de resíduos. Um dos seus

\footnotetext{
${ }^{1}$ Trabalho apresentado no Congresso Brasileiro Ciência e Sociedade (CBCS 2019), promovido pelo Centro Universitário Santo Agostinho, de 03 a 05 de outubro de 2019, em Teresina-PI.

${ }^{2}$ Graduando em Engenharia Civil, Centro Universitário Santo Agostinho, tassiotanic1@gmail.com

${ }^{3}$ Graduando em Engenharia Civil, Centro Universitário Santo Agostinho, hebertrodriguesss@outlook.com

${ }^{4}$ Mestra em Engenharia de Materiais, Instituto Federal do Piauí, Orientadora deste artigo, acilaynne@hotmail.com

${ }^{5}$ Graduando em Engenharia Civil, Centro Universitário Santo Agostinho, ricardo.carvalhosa@hotmail.com

${ }^{6}$ Graduando em Engenharia Civil, Centro Universitário Santo Agostinho, raphaelfsampaio@hotmail.com
} 


\section{CONQGEESSOCIENCIAESOCIEDADE

ANAIS CBCS 2019 | 3 a 5 de outubro de 2019 | Centro Universitário Santo Agostinho - Teresina - PI

grandes desafios é a combinação de operações produtivas com atividades que conduzam a um progresso sustentável consciente, menos ofensivo ao meio ambiente (PINTO,2005).

Consumindo cerca de $20 \%$ a $50 \%$ dos recursos naturais, fica claro que a construção civil é conhecida como encarregada por grande parte dos efeitos gerados no segmento ambiental, utilizando-se de matéria prima de fonte provinda de sedimentos aluviais, ou seja, de um ou mais rios, que no caso por exemplo se constitui a argila, areia e cascalho. Outro problema preocupante é a geração de Resíduos Sólidos na Construção e Demolição (RCD's) que são em maior parte os Resíduos Sólidos Urbanos (RSU), desempenhando assim a necessidade de uma mudança na organização privada e partes públicas que administram todo o cerco do problema (FERNANDES; AMORIM, 2014).

Os (RCD's) retratam em média, $50 \%$ da massa dos resíduos sólidos urbanos. Contudo, preocupando-se em diminuir o uso da matéria prima não renovável, se fez a necessidade de uso de um sistema de seguimento sustentável, quando se fala em resíduos sólidos da construção e demolição (RCD's) nas cidades brasileiras, onde no Brasil como em outros países, o seu depósito é feito em lugares inapropriados, sendo esses espaços irregulares, e aterros clandestino, causado por uma falta de gerenciamento, situação essa que gera grande impacto ambiental (ÂNGULO,2000).

\section{METODOLOGIA}

A pesquisa foi realizada no município de Teresina Piauí, o trabalho foi dividido em três etapas. A primeira etapa do projeto, sendo, a busca de conhecimento bibliográfico que fundamentou o referencial teórico do devido trabalho sobre os (RCD's) urbanos, assim, obtendo-se um conhecimento que serviu de base para coleta e interpretação de dados, comparações e validações na pesquisa cientifica realizada.

A segunda etapa refere-se ao levantamento de dados, desde a geração até a destinação final. Passando pela quantificação, triagem do resíduo e classificação.

A terceira e última etapa foi a agregação dos dados obtidos no levantamento em campo, interpretação de todas as informações levantadas. 0 estudo partiu dos seguintes agentes, dados 
ANAIS CBCS 2019 | 3 a 5 de outubro de 2019 | Centro Universitário Santo Agostinho - Teresina - PI

históricos do agente coletor, quantitativos e qualitativos de (RCD) coletado e disposição final feita no aterro onde hoje o único legalizado junto a prefeitura atualmente, respeitando todas a diretrizes no decreto № 18062 DE 18/10/2018.

Para este trabalho, foi utilizada uma pesquisa aplicada com uma abordagem qualitativa, em relação ao foco da investigação que é da deposição muitas vezes irregular de RCD em logradouros públicos do município de Teresina Piauí sendo a pesquisa qualitativa a que trabalha majoritariamente com dados qualitativos, ou seja, as informações apresentadas pelo pesquisador em números representam um papel menor na análise.

\section{RESULTADOS E DISCUSSÃO}

Para atingir o objetivo proposto, que foi identificar e analisar a política e os meios de controle, utilizados pela empresa " $A$ ", efetuou-se buscar por informações junto a essa empresa de coleta de entulho que já atua em Teresina há dez anos, passando assim por vários momentos de mudança no que rege a coleta dos (RCD`s), onde antes, era feito as coletas em obras, a empresa fazia a coleta e sem nenhum credenciamento do local, ou alvará de destinação era depositado ali os entulhos gerados na construção ou demolição, muitas vezes para aterrar um terreno particular, sem nenhuma fiscalização ou estudo de viabilidade.

Assim com o tempo foi se percebendo a necessidade de diminuir as Distâncias Médias de Transporte (DMT), pois por não ter um local especifico, ficava sempre a situação de busca de algum local com um terreno onde o proprietário, autorizasse a destinação, e assim com estudos feitos pela empresa, foi observado que o uso de usina de reciclagem, para a cidade de Teresina não era viável, pois o produto final de reciclagem se tornaria mais caro que o produto natural que temos em abundância, e assim não se teria uma demanda que compensasse os custos com essa reciclagem.

E assim com uma cobrança da prefeitura e a legislação federal, foi necessário o credenciamento de uma área particular, para o uso da destinação, onde todo o entulho é depositado nesse local, e assim há um tratamento com maquinário para a abertura do entulho e posteriormente, tem se uma associação de catadores, para a coleta de reciclados, e o que não pode ser reciclados, é separado para uma pilha de rejeitos, e o material que vai para o aterro são 
ANAIS CBCS 2019 | 3 a 5 de outubro de 2019 | Centro Universitário Santo Agostinho - Teresina - PI

materiais, típicos da construção como o concreto e o material cerâmico, e os demais materiais são levados para aterro sanitário da cidade.

Assim utilizando de dados fornecidos pela empresa, observando os quantitativos que se tornam estáveis a algum tempo, a média de coleta de entulhos é uma média de 250 caçambas por mês, isso gerando em torno de mais de $1000 \mathrm{~m}^{3}$ cúbicos de entulho coletado por mês pela empresa em estudo.

Em relação a destinação, conforme mostrado pela empresa, existe apenas um único lugar credenciado, junto a prefeitura, para a destinação dos resíduos. Sendo em torno de 33 empresas que cuidam da coleta e transporte dos entulhos na cidade, apenas a empresa em questão fazendo parte de uma associação de 7 outras empresas que também destinam seus "entulhos" nesse local adequado, mostrando assim que ainda existem muitas empresas clandestinas que destinam esses (RCD's) em locais irregulares.

\section{CONSIDERAÇÕES FINAIS}

Considerando que todo o resíduo gerado seja depositado em container privado para posteriormente ser levado para "aterros sanitários" ou em qualquer outra área que seja necessário a aterragem. Pode promover problemas como a escassez de áreas de aterro pelo seu grande volume. Para se reutilizar o RCD para aterros deve se tomar cuidado na hora da execução para evitar possíveis problemas em construções que possam vim a serem executadas no local, podendo sofrer entre outros problemas o recalque ou até mesmo desabamentos.

Embora a reciclagem seja a melhor alternativa para o entulho, toda via, na cidade de Teresina ainda não é uma alternativa viável pelo alto investimento necessário, assim o produto final, o material reciclado iria possuir um preço semelhante a matéria prima virgem extraída, por exemplo, o concreto ou "material cinza" como é chamado quando reciclado com o triturador poderia ser utilizado como agregado em traços de argamassas e concreto substituindo areia, mas por esse material ser tão abundante em Teresina, pois possui dois grandes rios bem próximo, acaba se tornando menos atrativo para os consumidores. 


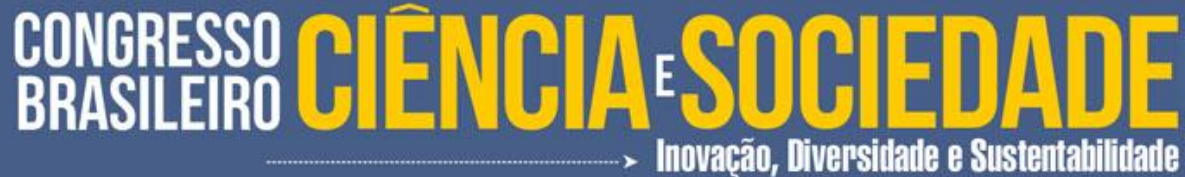

ANAIS CBCS 2019 | 3 a 5 de outubro de 2019 | Centro Universitário Santo Agostinho - Teresina - PI

Dessa forma, uma outra forma de minimizar os impactos ambientais seria a criação de aterros para resíduos sólidos da construção, que são mais baratos que aterros sanitários, também com a concentração desses resíduos em um só lugar facilita a classificação, processos de reutilização ou reciclagem. Atendendo as legislações municipais e a resolução 307/02 do CONOMA.

\section{REFERÊNCIAS}

ÂNGULO, S.C. Variabilidade de agregados graúdos de resíduos de construção e demolição reciclados. São Paulo, 2000. 155p. Dissertação (Mestrado) - Escola Politécnica, Universidade de São Paulo.

CONAMA - CONSELHO NACIONAL DO MEIO AMBIENTE (2002) Resolução no 307, de 5 de julho de 2002. Estabelece diretrizes, critérios e procedimentos para a gestão dos resíduos da construção civil. Brasília: Diário Oficial da União; 2002.

FERNANDES; AMORIM, Cadernos de Graduação - Ciências Exatas e Tecnológicas Unit 2, 1 (2014).

PINTO, Tarcísio de P.; GONZÁLES, Juan L.R. (Coord.). (2005) Manejo e gestão dos resíduos da construção civil. Brasília: CAIXA. 